\title{
富栄養化した浅い湖沼における水生植物（マクロファイト）のモテル化と 藻類の増殖に与える影䇾の検討
}

Modeling of macrophytes and their effects on algal blooming in a shallow eutrophic lake

\author{
浅枝 隆*、チュオング ボン バン**、有田正光***
} by Takashi Asaeda, Truong Van Bon, Masamitsu Arita

\begin{abstract}
An eutrophication model, incorporating phytoplankton, submerged macrophytes and nutrient dynamics in sediments was developed to be a functional tool for understanding the effects of macrophytes on algal blooming in shallow lakes. The model was applied to the Lake Veluwe experiment, successfully reproducing seasonal change in the lake. such as the transition of the dominant species of phytoplankton from diatom during spring, green algae in summer, and to blue green in late autumn depending on the nutrient and light condition. nutrient concentration in the water, as well as the yearly life-cycle of macrophytes.
\end{abstract}

Keywords: Eutrophication; Macrophytes; Phytoplankton; Nutrient Cycle; Lake Restoration

1.はじめに

浅い湖沼においては、主要な生産者として植物プランクトンと同時に水生植物（マクロファイト）が大 きな㗢きを行っている。このマクロファイトは、周囲の水との直接的に、また、湖底の土壤を介在させて、 浅い湖沼の物理的、化学的、生物的環境を大きく左右する。このため、近年ではこのマクロファイトを利 用して湖沼の浄化を図る試みが各地で始められており、その予測、評価は環境水理学の一つの大きなテー マといってよい。環境水理学が流れと環境要素との相互関係を対象とする学問であるとすれば、高度に予 測技術の発達した湖沼内の流れの解析と同時に、こうした環境にとって極めて大きな役割を果たす生物的 な環境要素も同時に組みこんでいく必要がある。

本研究ではこうした背景を考虑して、マクロファイト（ここでは沈水性植物を取り扱う）のモテル化を 試み、土壌内の栄湌塩循環、植物プランクトンなどの他の要素と組み合わせることによって、マクロファ イトと植物プランクトンの競合関係を再現することを試みた。

\section{2. 全体のモテルの梅略}

全体のモテルは、図 1 に示されるように、大きく植物プランクトンの增殖および水中の栄養塩収支のモ テル、湖底の土墒中の酸素や栄着塩の循環モテル、マクロファイトの成長モテルの3つに分けられる。こ こでは特にマクロファイトのモテルを中心に説明を加える。水生植物が水質や藻類に及ぼす効果として、 このモテルで考虑したものの他に、湖底の土壤に酸素を供給しリン酸塩の溶出を抑制したり、種によって はallelopathicな物質により、藻類の增殖を押さえるという働きがある。しかし、これらについては現在の ところ知見がそしく本モテルには含んでいない。特に、ここで取り扱っているリュウノヒゲモ、 Potamogeton pectinatus、については、allelopathy効果は確認されておらず、また、土壤中の酸素につい ても酸素の拡散範囲が根の周辺に限られていることを考虑すれば、こうした動きを含まなくても現象の特 性を十分表現できているものと考えられる。

\section{3. マクロファイトのモデの概要}

ここでは、観測テータが豊富に存在することから、リュウノヒゲモ、Potamogeton pectinatus L.を対象 にする。まず、Potamogeton pectinatus L.を荎、葉(shoot)、新しく発生する葉、菱 (secondary shoot)、

\begin{tabular}{|c|c|c|c|c|}
\hline i & 溥 & & 338 & \\
\hline 学 & 工 & & 専攻 & 浦 \\
\hline 正会員 & 工博 & 東京電機大学教授 & 理工学部建設工学科 & 奇玉 \\
\hline
\end{tabular}




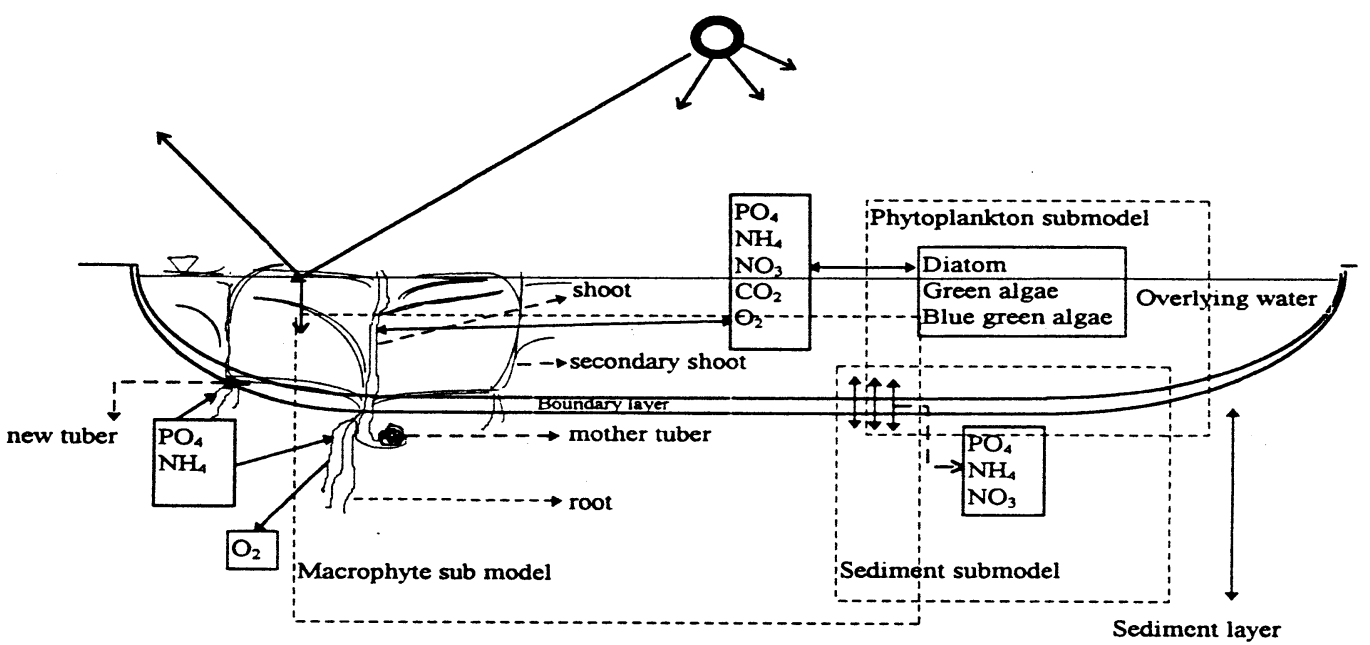

図1モテルの概略図

根 (root)、元々の根茎 (tuber)、新しく発生する根茎 (secondary tuber)に分け、それぞれについての成長、 衰退を追跡していく。これらのバイオマスの時間変化は、次のような式で表される。

$\frac{B_{s h t}}{a}=P h_{s h t}-R_{s h t}-D e_{s h t}+C_{d} \cdot D e_{s h t}^{p}+T_{f} \cdot f\left(j_{s t}\right)-L_{s e c} \cdot \max \left[0, F_{s h t}\right]-f_{s h t} \cdot \varepsilon_{s h t} \cdot B_{s h t}$

$\frac{\partial B_{\mathrm{sec}}}{2}=P h_{\mathrm{sec}}-R_{\mathrm{sec}}-D e_{\mathrm{sec}}+C_{d} \cdot D e_{\mathrm{sec}}^{p}+L_{\mathrm{sec}} \cdot \max \left[0, F_{\mathrm{sht}}\right]-f_{\mathrm{sec}} \cdot \varepsilon_{\mathrm{sec}} \cdot B_{\mathrm{sec}}$

$\frac{\partial B_{r t}}{\partial}=G_{r t} R_{r t}-R_{r t}-D e_{r t}+C_{d} \cdot D e_{r t}^{p}-N_{t f} f(j)$

$\frac{\partial B_{t u b}}{a}=-R_{t u b}-D e c t_{t u b}-T_{f} \cdot f\left(j_{s t}\right)$

$\frac{B_{\text {ntub }}}{2}=G_{b t u b} R_{\text {ntub }}-R_{\text {ntub }}-D_{\text {ntub }}+N_{t f} \cdot f(j)+f_{\text {sht }} \cdot \varepsilon_{\text {sht }} \cdot B_{\text {sht }}+f_{\mathrm{sec}} \cdot \varepsilon_{\mathrm{sec}} \cdot B_{\mathrm{sec}}$

ここで、葉茎で形成されるエネルギーの余剩分は根茎を形成するために費やされる。すなわち、葉茎から 新しく根茎を形成するためのエネルギーの移動を表す係数fは次のように表せる。

$f_{s h t}=0$ if $P h_{s h t}-R_{s h t}-D e_{s h t}+C_{d} \cdot D e_{s h t}^{p}+T_{f}-L_{\mathrm{sec}} \cdot \max \left[0, F_{s h t}\right] \geq 0$

$f_{s h t}=1$ if $P h_{s h t}-R_{s h t}-D e_{s h t}+C_{d} \cdot D e_{s h t}^{p}+T_{f}-L_{s e c} \cdot \max \left[0 . F_{s h t}\right] \prec 0$

$f_{\mathrm{sec}}=0$ if $P h_{\mathrm{sec}}-R_{\mathrm{sec}}-D e_{\mathrm{sec}}+C_{d} \cdot D e_{\mathrm{sec}}^{p}+L_{\mathrm{sec}} \cdot \max \left[0, F_{\text {sht }}\right] \geq 0$

$f_{\mathrm{sec}}=1$ if $P h_{\mathrm{sec}}-R_{\mathrm{sec}}-D e_{\mathrm{sec}}+C_{d} \cdot D e_{\mathrm{sec}}^{p}+L_{\mathrm{sec}} \cdot \max \left[0, F_{s h t}\right] \prec 0$

$\max 0, F_{\text {sht }}=0$ if $F_{\text {sht }} \leq 0 ; \max 0, F_{\text {sht }}=F_{\text {sht }}$ if $F_{\text {sht }} \succ 0$

ただし、それぞれの記号は次の意味を示す。

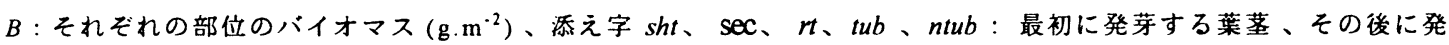

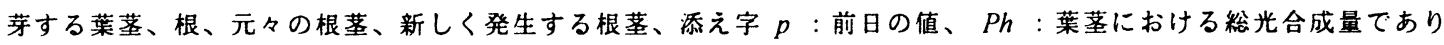
$\left(\mathrm{g} \cdot \mathrm{m}^{-2} \mathrm{~d}^{-1}\right) 、 R:$ 呼吸量 $\left(\mathrm{g} \cdot \mathrm{m}^{-2} \mathrm{~d}^{-1}\right) 、 C_{d}:$ 枯死した部分から生存している部位へのエネルギー移動量の割合、De : 


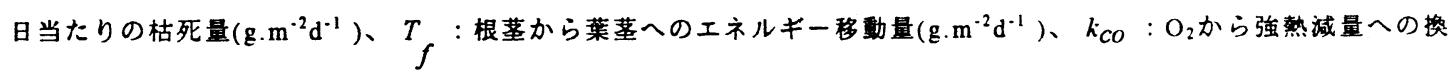

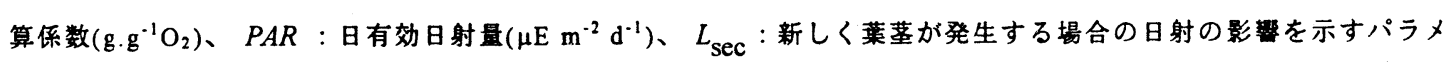
一夕; $\varepsilon_{s h t} 、 \varepsilon_{\mathrm{sec}} 、 N_{t f}$ : 新しい根茎の成長を促すための 莱茎および根からのエネルギー移動、 $G_{r t} 、 G_{n t u b}$ ：根 と葉茎の成長速度、 $f(j): j \prec j_{s t}+7$ のを $0 、 j \geq j_{s t}+7$ のときを表す関数、 $j_{s t}$ ：成長が始まってからの日数、 $F_{s h t}=P h_{s h t}-R_{s h t}-D e_{s h t}+C_{d} \cdot D e_{s h t}^{p}+T_{f^{\circ}}$

なお、大部分の俰数は文献 (Madson \& Adams 1989, Viersen et al 1989等) から引用しているが、記録 のないいくつかについてはキャリブレーションにより決定した（詳しくはAsaeda \&Bon,1996参照）。

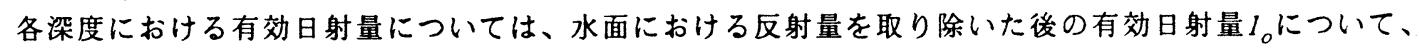
水質 $\eta_{w}$ 、藻類の量 $\eta_{c} . C h l 、$ そ水梁 $z$ 以浅のマクロファイト自体のバイオマス量 $\eta_{m} \cdot M A C$ の関数として次 のように表される。

$I=I_{o} \cdot e^{-\left(\eta_{w}+\eta_{c} \cdot C h l+\eta_{m} \cdot M A C\right) \cdot z}$

最初に発生する葉茎の数 $N O_{p l t}$ は $N O_{p l t}=B_{t u b}(j) / B_{o}$ で定まる。ただし、ここで $B_{t u b}(j)$ は $j$ 日目の蓄 皘したエネルギーであり、 $B_{0}$ は初期の葉茎のバイオマス量である。

光合成量は日射量、日路、特に土㙥内のアンモニア態窒素およびリン酸態リンの量で定まると考えら れる。従って、Michaelis-Menten型の関係を用いて、

$P h_{\text {sht }, \text { or sec }}=k_{c o} \cdot P_{m} \cdot \frac{P O_{a v}}{K_{P}+P O_{a v}} \cdot \frac{N H_{a v}}{K_{N}+N H_{a v}} \cdot \frac{P A R}{K_{p a r}+P A R} \cdot \frac{K_{a g e}}{K_{a g e}+A g e} \cdot B_{s h t, o r \mathrm{sec}}$,

で与えることにする。ここで、 $P_{m}$ は最大光合成量 $\left(\mathrm{g} . \mathrm{O}_{2} \mathrm{~g}^{-1} \mathrm{~h}^{-1}\right) 、 A g e$ は葉菱の日齢 $(\mathrm{d}) 、 K_{N} 、 K_{P} 、 K_{\text {age }}$ および $K_{p a r}$ は土袞間吵中のアンモニアおよびリン酸態リンの濃度、日䊀、日射についての光合成量に対す る半飽和定数 $\left(\mathrm{g} \mathrm{N}^{-\mathrm{m}^{-3}}\right)$ を表す。ここで、根の密度等十分な情報が得られないために、複雑にすることを

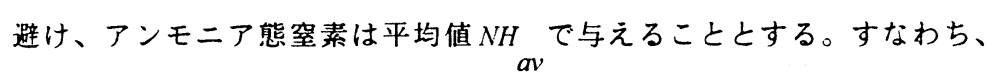

$N H_{a v}=\sum_{i=1}^{4} N H(i) \cdot \alpha_{i} z_{i} / \sum_{i=1}^{4} \alpha_{i} z_{i}$

最大光合成量および半飽和定数、呼吸量は実験より水温の関数として与えられる(Madsen \& Adams, 1989)。すなわち、mg Cから

$P_{m}=(0.1032 . T+2.55) 、 K_{\text {par }}=349-4.99 x T 、 \beta_{\text {sht }, \text { sec }, r t, t u b}=-T^{2} \times 6.7 \times 10^{-4}+0.482$

ただし、ここで、 $\beta_{s h t 、} \beta_{s e c} 、 \beta_{r t} 、 \beta_{t u b}$ はそれぞれ最初に発芽した葉荎、その後に発芽した葉荎、根、 根茎の呼吸量 $\left(\mathrm{d}^{-1}\right)$ を示す。

水中のバイオマス量の増加は、葉茎の上向きの成長量とその梁度におけるバイオマス量の增加とに分 けられる。それぞれの上向きへの成長量は、

$$
\Delta h_{s h t}=E T \frac{\Delta B_{s h t}(t o p)}{B_{r}} \text { および、 } \Delta h_{\mathrm{sec}}=E T \frac{\Delta B_{\mathrm{sec}}(\text { top })}{B_{r}}
$$


で与えられる。ただし、 $B_{r}\left(=0.1 \mathrm{~g} \mathrm{~m}^{-1}\right)$ は単位長さ当たりの、葉茎のバイオマス量である。また、 $\Delta B_{\text {sht }}(t o p)$ および $\Delta B_{\mathrm{sec}}{ }^{(t o p)}$ は最頂部のバイオマスの增加量であり、ET は最頂部に達する日射量の関数で ある。

初期の葉茎はジュリアン日 $j_{s t}$ から成長を始め、根茎より $B_{t u b}=0$ となるまで $T_{f}=0.15 B_{t u b}$ のエネルギーを 供給される。初期の根茎は一樣に0.006 g afdwと仮定した。残りのエネルギー分は日射量が $200 \mu \mathrm{E} \mathrm{m} \mathrm{m}^{-2} \mathrm{~s}$ ${ }^{1}$ に達した後は新しい葉茎の成長に向けられる。なお、元々の葉茎へのエネルギー輸送量への差し引き分 $F_{\text {sht }}$ が正になった後に、 $L_{\mathrm{sec}} \max \left[0, F_{\text {sht }}\right]$ を元に新しい葉茎が発生を開始し、残りのエネルギー $\left(1-L_{\mathrm{sec}}\right) \max \left[0, F_{\text {sht }}\right]$ は元々の葉茎の成長に当てられるものとした。ただし、 $L_{\mathrm{sec}}$ は湖底における日射量 の関数である。

葉茎、根、新しい根荎の呼吸量と枯死量はそれぞれのバイオマスに比例するものとし、次のように与 える。

$R_{\text {sht }}=\beta_{\text {sht }} \cdot B_{\text {sht }} ; R_{\mathrm{sec}}=\beta_{\mathrm{sec}} \cdot B_{\mathrm{sec}} ; R_{r t}=\beta_{r t} \cdot B_{r t} ; R_{\text {ntub }}=\beta_{\text {ntub }} \cdot B_{\text {ntub }}$

$D e_{s h t}=\gamma_{s h t} \cdot{ }_{s h t} ; D e_{\sec }-\gamma_{\mathrm{sec}} \cdot B_{\mathrm{sec}} ; D e_{r t}=\gamma_{r t} \cdot B_{r t}: D e_{n t u b}=\gamma_{n t u b} \cdot B_{n t u b}$

ここで、 $\beta$ および $\gamma$ はそれぞれの呼吸率および枯死率である。ただし、枯死率 $\gamma_{s h t}\left(\mathrm{~d}^{-1}\right)$ およひ $\gamma_{\mathrm{sec}}\left(\mathrm{d}^{-1}\right)$ は全体のエネルギー量の現象に伴って增大すると考えられる。そこで、これらの量をエネルギー枯渴量の 関数で与え、それぞれ、

$$
\gamma_{s h t}=r_{s h t} \frac{k_{s h t}}{k_{s h t}+P h_{s h t}-R_{s h t}+C_{d} \cdot D e_{s h t}^{p}} 、 \quad \gamma_{\mathrm{sec}}=r_{\mathrm{sec}} \frac{k_{\mathrm{sec}}}{k_{\mathrm{sec}}+P h_{\mathrm{sec}}-R_{\mathrm{sec}}+C_{d} \cdot D e_{\mathrm{sec}}^{p}}
$$

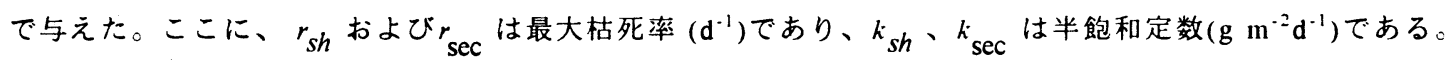
日射量についての計算結果より、根の成長の開始は全体の成長が始まって 2 ヶ月経った後となった。根の バイオマスの増加率はバイオマスと成長率との積として $G R_{r t}=G_{r t} \cdot B_{r t}$ で与えられる。ただし、観測値より $G_{r t}=0.2 \mathrm{~d}^{-1}$ である(Vierssen et al, 1994)。根が発達して後、その一部 $N_{t f}(=0.01)$ は新しい根茎の成長に利 用される。この新しい根茎の成長は $G R_{r t}=G_{n t u b} \cdot B_{n t u b}$ で与えられる。ただし、 $G_{n t u b}=0.2 \mathrm{~d}^{-1}$ である。

Vierssen, et al. (1994)によると、根は $20 \mathrm{~cm}$ の梁さに $5 \mathrm{~g} / \mathrm{m}^{2}$ の密度で分布していた。これに従って、根 全体のバイオマスが一定密度 $25 \mathrm{~g} / \mathrm{m}^{3}$ で分布するよう分布する梁さを定めるものとした。

新しい根茎は、日射量が $200 \mu \mathrm{E} \mathrm{m} \mathrm{m}^{-2} \mathrm{~d}^{-1}$ を越えれば成長が始まって 1 週間以内に成長を開始する(Vierssen, et al. 1994)。元々の根茎は、成長が始まった後、葉茎へのエネルギー供給 $T_{f}=\alpha_{t u b} \cdot B_{t u b}$ 、呼吸 $R_{t u b}=\beta_{t u b} \cdot B_{t u b}$ 、枯死 $D e c{ }_{t u b}-\gamma_{t u b} \cdot{ }_{t u b}$ のために徐々に縮小する。一方、新しい根茎は根からのエネルギー 供給 $N_{t f}$ 、葉茎からの余分のエネルギーの流入、 $f_{s h t} \cdot \varepsilon_{s h t} \cdot B_{s h t}$ および $f_{\mathrm{sec}} \cdot \varepsilon_{\mathrm{sec}} \cdot B_{\mathrm{sec}}$ 、を受けるがその一部は 呼吸と枯死によって失われる。

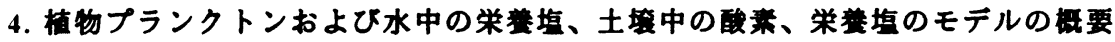

水中の栄養塩および植物プランクトンについては多数のモテルが提案されている。こここでは、 Hamilton \& Schladow (1994)、Nimal et al(1996)の提案したモテルを元に改良を加えた。ここでは、考え る植物プランクトンは、緑藻、珪藻、藍藻とし、問題はあるもののクロロフィルaを指標にその量を表す 
ことにした。バイオマス量の変化、藻類の体内の室素およびン、水中のオルトリン酸、アンモニア、硝 酸、珪素、溶存性酸素、BODの濃度についての保存則を用いた。

湖沼の土壤内の酸素、栄養塩の移動に ついては、図 2 に示されるように土壤を 酸化層、眖窒層、還元層上部、退元層下 部およびテトリタスの堆積による土壤と 水中との間の境界層とに分け、それぞれ について、テトリタス、硝酸性窒素、ア ンモニア性窒素、酸素、リン酸について の保存則より求めた(Bon and Asaeda, 1996)。計算にあたっては、全体の水柱 を200層に分割した。それそれの層厚は 約 $10 \mathrm{~cm}$ 程度である。また、土壤中につい ては、マクロファイトの影響が大きいと 考えられる水底より $20 \mathrm{~cm}$ の深さを計算 の対象とし、化学的特性に応じて 4 分割 した。

\section{5.対象とした湖の概要}

対象としてはデータの完備している Lake Veluweについて1986年の1月から 12月について行った。この湖は面積 32.8 $\mathrm{km}^{2}$ 平均水樑 $2 \mathrm{~m}$ の湖であり、特に、東お よび南側については $1 \mathrm{~m}$ 以内の浅瀬とな っている。1960年代までは浅い部分は Potamogeton pectinatus Lに覆われてい た。ところが、富栄着化により1969年以 降P. pectinatus L.は徐々に姿を消し始 め、その後1979年より流域からのリンの 流出の抑制、硝酸性窒素やカルシウムに 富んだ水によるフラッシングにより再び 回復し始め、逆に、植物プランクトンに ついてはそれまで支配的だった藍藻が減 少し、理藻、緑藻が卓越することになっ た(Vierssen, et al. 1994)。

入力テー夕としては、気象条件 (Vierssen, et al. 1994)の他に、栄養塩お よび流量についてのデータが必要になる が、こではできるだけ単純化し、Bon \& Asaeda(1996)と同様なものを用いた。な お、マクロファイトの成長の開始日は観

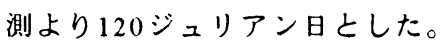

\section{6. 結果および考察}

図 3 藻類の種別変化を観測値と伴に示 す。ここでは、藻類それそれれの特性值に 提案された值のほぼ中間的な值を用いて いるが、藻類の要移についてもよく再現 されているといえる。計算過程の検討に よると、1-2月の珪藻のブルーミング は珪藻の低い半飽和定数によっており、

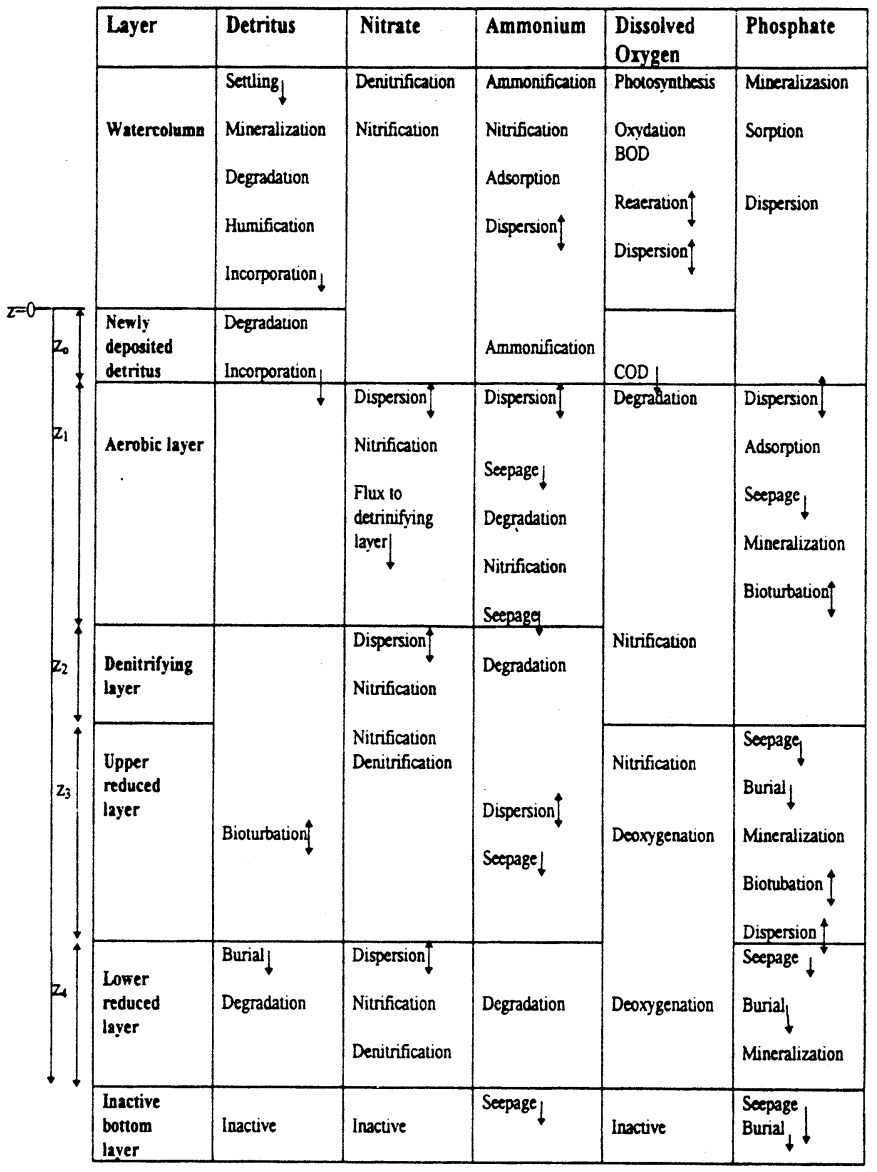

図 2 土壤中の酸素、栄養塩の移動モデルの概略

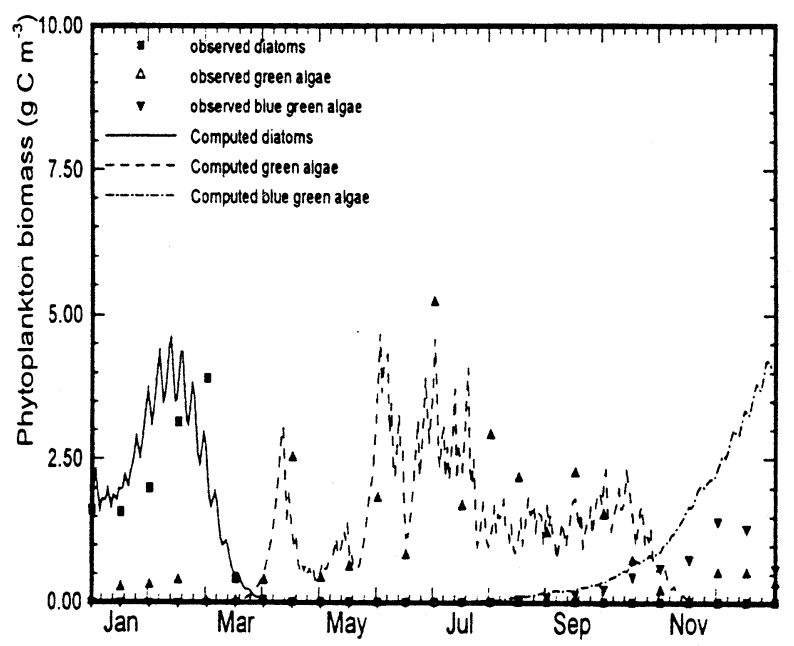

図 3 藻類の種別変化 
緑藻への変化はその高い増殖速度によっ ている。また、藍藻への要移は細胞内に 必要とするリンの量がより少量でよいこ とおよび成長がより低い光量で飽和する ためである。なお、冬場の硝酸塩の増加 は主としてフラッシングによるものであ り、これは年間の変化でみれば藍藻およ び珪藻の増加を促していることが伺え る。

図4にマクロファイトの全バイオマス 量、部分別のバイオマス量を示す。全バ イオマス量について観測值と比較すると 概ね一致しているが、9 月以降の過大評 価が目立つ。これは、この時期には風波 が高くなり機械的に破壊される割合が高 くなるが、モテルではこうした点を考虑 していないためである。前年度からの根 荎は成長開始後すぐに利用され尽くして しまい、根および新しい根茎と受け継が れ翌年の成長につながっていることがわ かる。また、6月に成長速度がやや低下 するのは、緑藻の発生により光量が減少 したためであり、光をめぐる競合の結果 である。

図 5 はリンの溶出速度の計算結果をマ クロファイトの存在する場合としない場 合とについて比較したものである。なお、 観測は参考のためにりン酸の濃度を示し ている。マクロファイトによって土壤中 のリン濃度の変動が和らげられるため に、マクロファイトの存在している場合 にはしない場合に比較してリンの溶出速 度が滑らかになっていることがわかる。

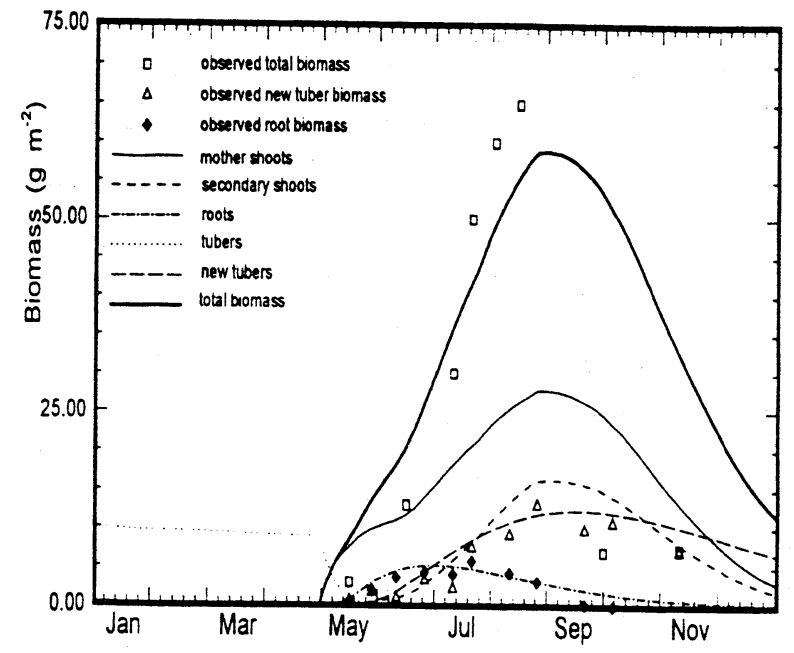

図 4 マクロファイトの部分別バイオマス量の変化

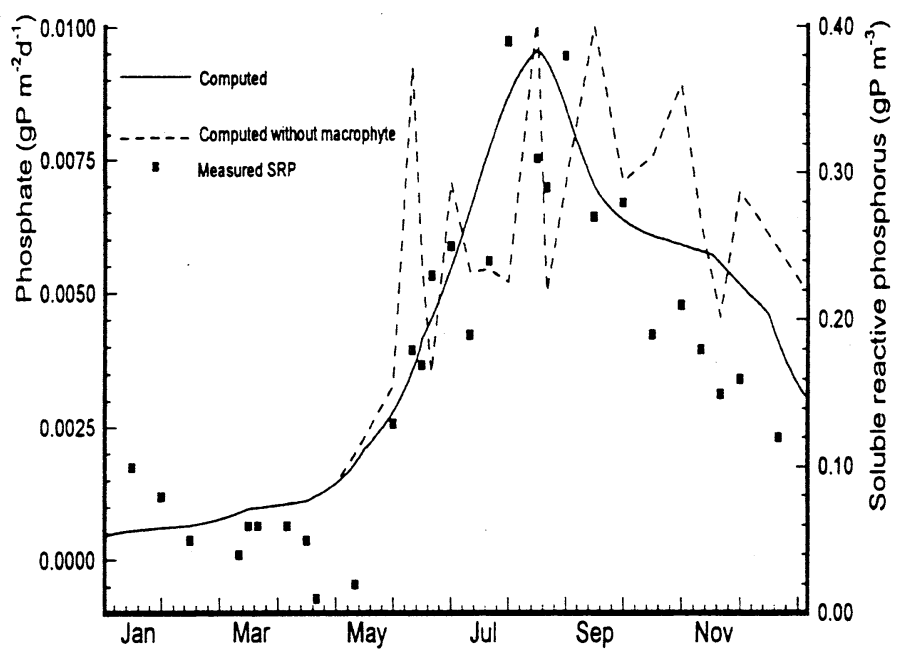

図 5 リンの溶出速度に対するマクロファイトの影響

\section{7. 結 语}

浅い湖沼におけるマクロファイトの役割は極めて大きい。しかしながら、現状では経験的にのみその重 要性が明らかにされており、環境水理学の手法である保存則の導入は必ずしも十分とはいえず、精緻な水 の流動との関連性を定量的に議論することはほぼ不可能である。そのため、まず、これまで報告されてい る諸々の現象についての経験的な関係を用いてマクロファイトバイオマスの成長を記述する式の構築を行 った。結果は、ほぼすへてについて、それぞれの諸現象について経験的に得られている係数を用いれば、 ほとんどキャリブレーションの必要なく概略現状の再現が可能であった。また、これによって藻類との競 合などいくつかの重要な現象の記述が可能となった。

本研究を行うにあたり、河川環境整備盰団からの補助を受けた。記して感謝いたします。

1 ) Asaeda,T.\&Bon,T.V., 1996, Ecological Modelling (submitted).

2) Bon, T.V. \&Asaeda, T., 1996, 噮境

システムステム研究, 24. 3) Bon, T.V.\&Asaeda,T, 1997., 水工学論文集, 41.4 ) Hamilton, D.P. and Schladow, S.G., 1994, Report No ED 597DH, CWR, UWA, 29 pp. 5 ) Nimal, et al, 1996., 水工学論文集, 40. 5 ) Madsen, J.D. and Adams, M.S., 1989. Aquat. Bot., 36:23-31. 6) Vierssen,W.V., M.J.M. Hootsmans, M.J.M,\& J. Vermaat, J.

(Editors), Lake Veluwe, Kluwer Academic Publishers. 